\title{
A MULTI-SCALE APPROCH FOR RETREIVING PROPORTIONAL COVER OF LIFE FORMS
}

\author{
Ursula Gessner ${ }^{1}$, Christopher Conrad ${ }^{1}$, Christian Hüttich ${ }^{1}$, Manfred Keil ${ }^{2}$, Michael Schmidt ${ }^{1,2}$, \\ Matthias Schramm ${ }^{1}$, Stefan Dech ${ }^{1,2}$ \\ ${ }^{1}$ Remote Sensing Unit of DLR \\ University of Wuerzburg \\ Wuerzburg, Germany \\ e-mail: ursula.gessner@uni-wuerzburg.de \\ ${ }^{2}$ German Remote Sensing Data Center \\ German Aerospace Center (DLR) \\ Oberpfaffenhofen, Germany
}

\begin{abstract}
This study presents a multi-scale procedure to derive continuous proportional cover of woody vegetation in savanna ecosystems. QuickBird data was classified to define a continuous training and validation data set of woody cover proportions. Using a regression tree algorithm based on Landsat TM data, this woody cover information was extrapolated to an area of approximately $185 \mathrm{~km} \times 185 \mathrm{~km}$. The resulting $30 \mathrm{~m}$ map of the Namibian North-eastern Kalahari Woodland was aggregated to $250 \mathrm{~m}$ and $500 \mathrm{~m}$ resolutions. Comparisons of the global MODIS VCF product with the regionally adjusted multi-scale fractional cover map indicate that VCF tree cover is generally underestimated in the study area and confusions between tree and dense shrub cover occur.
\end{abstract}

Index Terms - fractional cover, regression tree, multiscale analysis, savanna, VCF

\section{INTRODUCTION}

Present-day ecosystems are continually impacted by climate change and anthropogenic pressures on natural resources. This is especially true for southern African savannas where during the last decades, human activities have strongly affected the natural composition of life forms, i.e. the herbaceous and woody cover proportions, both proximate through for instance clearing and indirectly through human induced climate change or land tenure shifts [1]. Global savannas make up just under one third of the world's land surface, and both changes in $\mathrm{CO}_{2}$ levels from anthropogenic emissions and livestock grazing may result in woody vegetation to become more dominant over herbaceous life forms. While an in-depth understanding of ecosystem states and processes requires spatially explicit, area-wide and reliable knowledge of the fractional cover of key life forms, this kind of detailed information is missing for the major part of southern African savanna ecosystems. Life form maps of savannas are either compiled for limited areas [e.g. 2] or in global approaches with a comprehensible subsequent weakness in regional detail and accuracy [3], often requiring further validation with rigorous sampling methods [4].

In this study, we derived multi-scale cover estimates of woody vegetation (i.e. trees and shrubs) for the Namibian North-eastern Kalahari Woodland, a characteristic example of a savanna affected by various processes altering the surface fraction of woody plants. This region is of special interest as during the last decades, it has been subject to a pronounced population growth with subsequent expansion and intensification of land use patterns. Important processes are for example the clearing of woody vegetation for agricultural land use, changing fire regimes and dense shrub growth on abandoned fields. These changes can destabilise the affected ecosystem and alter its carbon storage capacity and biodiversity patterns. The fractional cover information derived in the presented multi-scale approach is an important step towards a detailed inventory of woody vegetation in savanna ecosystems and an important requirement for the study of change processes in these regions.

\section{DATA AND METHODS}

Continuous values indicating the proportional cover of woody vegetation were estimated in a multi-scale procedure. The analysis incorporated QuickBird and Landsat TM data acquired during the rainy season 2007 with a time lag of approximately 2 months. 
QuickBird data were analysed in order to derive detailed information on woody subpixel cover of the $30 \mathrm{~m}$ Landsat TM data. For this purpose, it was classified into four classes with distinct surface cover compositions and aggregated to proportions of woody cover within $30 \mathrm{~m}$ Landsat TM cells. In order to fully exploit the $0.6 \mathrm{~m}$ resolution of QuickBird, the panchromatic and multispectral bands were combined in a high pass filter based resolution merge. Subsequently, the very high resolution data were classified in a combined segment-oriented and pixel-based approach. Subsets of QuickBird data, equally spaced on a $3 \mathrm{~km}$-grid and covering $360 \mathrm{~m} \times 360 \mathrm{~m}$ each, were segmented with an optimized segmentation procedure following [5]. On the basis of the created segments, training areas were derived for a maximum likelihood classification on pixel level. The four classes distinguished in this classification are listed in the first column of Table 1. Even on QuickBird scale, three of these classes (herbaceous dominated, soil dominated and shadow) are not characterized by one single cover type but are made up of a mixture of bare ground, herbaceous and woody vegetation. The mean surface cover composition of the classes herbaceous dominated and soil dominated was therefore identified with the help of ground truth data (Table 1). The cover composition of the class shadow was defined by assuming shadow to be equally distributed over all other classes. Given the overall distribution of the class woody dominated, herbaceous dominated and soil dominated of $33 \%, 41 \%$ and $26 \%$ respectively, shadow was suggested to contain the same fractions of classes. Accordingly, the actual fractions of woody, herbaceous and bare surface could also be calculated for the class shadow (Table 1).

Table 1: Class definition of the QuickBird classification.

\begin{tabular}{cccc} 
& \multicolumn{3}{c}{ composition } \\
\cline { 2 - 4 } & $\begin{array}{c}\text { woody cover } \\
{[\%]}\end{array}$ & $\begin{array}{c}\text { herbaceous } \\
\text { cover [\%] }\end{array}$ & $\begin{array}{c}\text { soil cover } \\
{[\%]}\end{array}$ \\
$\begin{array}{c}\text { woody } \\
\text { dominated }\end{array}$ & 100 & 0 & 0 \\
\hline $\begin{array}{c}\text { herbaceous } \\
\text { dominated }\end{array}$ & 10 & 60 & 30 \\
\hline $\begin{array}{c}\text { soil } \\
\text { dominated }\end{array}$ & 0 & 30 & 70 \\
\hline shadow & 37 & 32 & 31
\end{tabular}

The QuickBird-derived woody cover was aggregated to continuous cover values on Landsat TM pixel level, where each $60 \mathrm{~cm}$ pixel was weighted according to its intersection with the corresponding $30 \mathrm{~m}$ cell. From these aggregated classification results, training and validation samples were extracted using stratified equalized sampling. In order to expand the estimation of woody cover to the whole of the Landsat TM scene, the $30 \mathrm{~m}$ sub-pixel information was used as training data for a regression tree analysis [6]. Nonparametric regression trees have been used successfully in a number of studies for the analysis of remote sensing data [e.g. 7, 8]. A regression tree was grown with the independent variables being bands 1 to 5 and 7 as well as the Simple Ratio, NDVI, SAVI and the Tasseled Cap Greenness, Brightness and Wetness of the Landsat TM data. Similar to [7], linear regression models were fitted for each individual leaf, in order to produce more continuous results. In this step, the independent Landsat TM feature, which best explains the cover values of each terminal node, was used to enhance the prediction of woody cover. The structure of the regression tree shows that vegetation indices (SAVI and NDVI) were chosen for the first splits whereas Landsat TM band 5 was showing highest correlations with woody cover for the leaf-wise linear regression.

To assess the accuracy of the final map, the $30 \mathrm{~m}$ continuous values of woody cover derived from Landsat TM data were compared with the validation data extracted from the aggregated QuickBird classification and the correlation coefficient $(\mathrm{n}=4700)$ was calculated. Finally, the $30 \mathrm{~m}$ results were scaled to a resolution of $250 \mathrm{~m}$ and $500 \mathrm{~m}$, analysed for their information content and compared to the MODIS product Vegetation Continuous Fields VCF [3].

\section{RESULTS AND DISCUSSION}

Figure 1 shows the map of woody vegetation cover for the Namibian North-eastern Kalahari Woodland as derived in the presented multi-scale approach. The comparison with the validation sample set yielded a correlation coefficient $R^{2}$ of 0.79 .

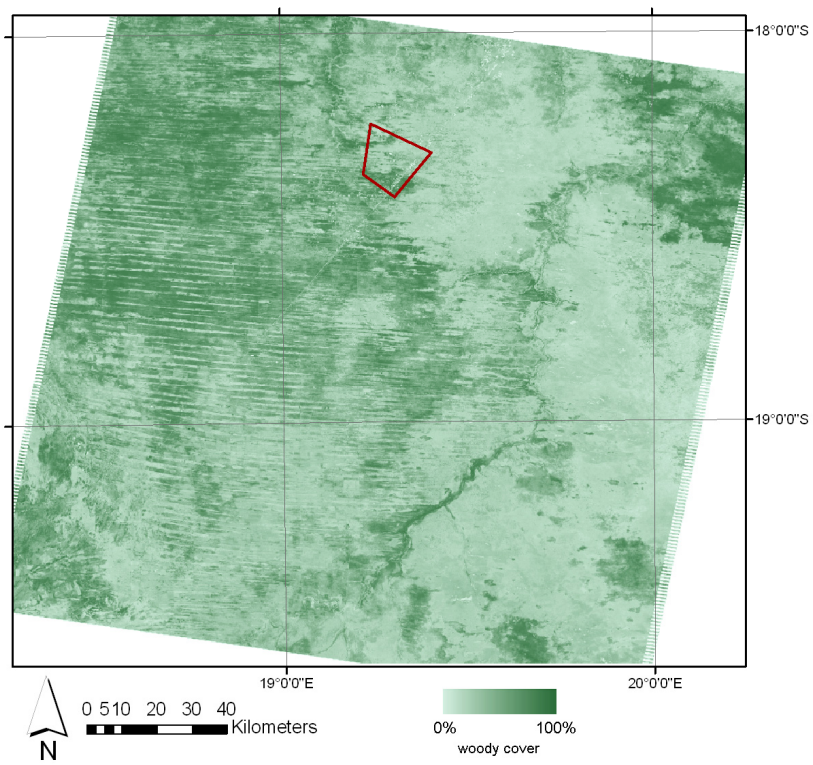

Figure 1: Fractional woody cover of the North-eastern Kalahari Woodland as derived from Landsat TM data for the year 2007. The extent of the QuickBird acquisition which was used for training data definition is marked in red. 

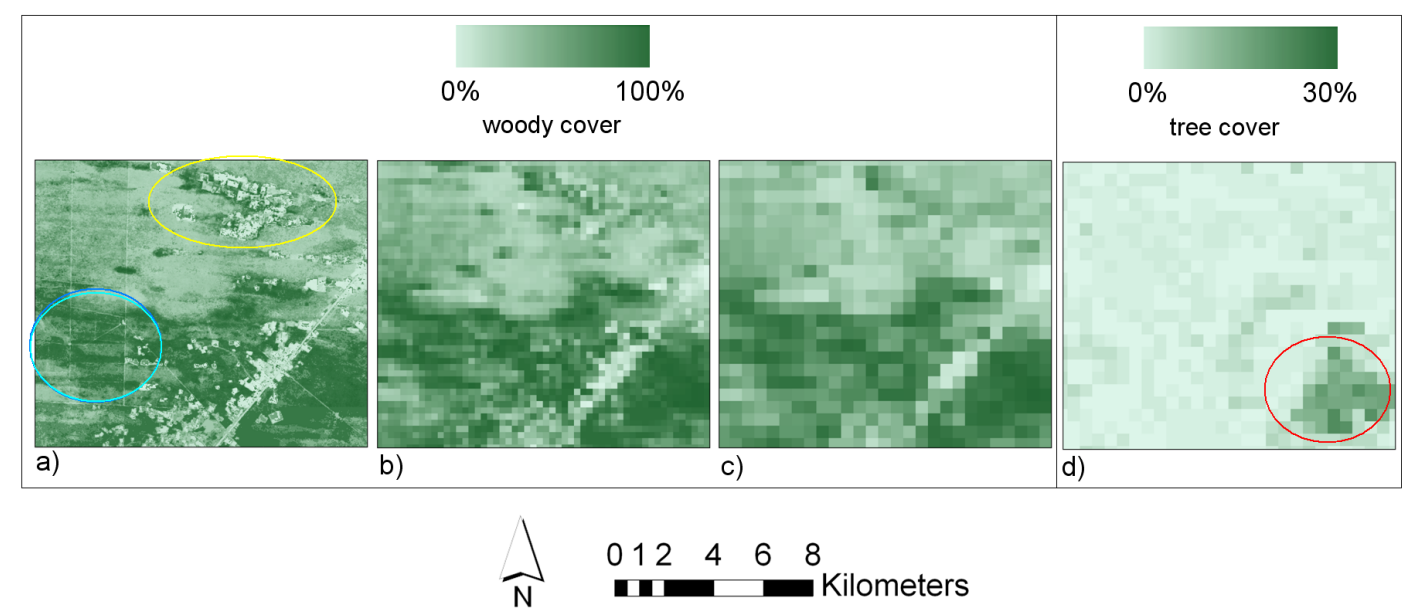

Figure 2: Subset of the fractional woody cover map as derived from Landsat TM data. Areas of special interest are highlighted. a) Original resolution: $30 \mathrm{~m}$;

b) Aggregated to a cell size of $250 \mathrm{~m}$;

c) Aggregated to a cell size of $500 \mathrm{~m}$;

d) MODIS VCF version 3 percent tree cover layer

The map adequately describes the smooth transitions between open and closed shrub- and woodlands which are typical for Namibian savanna landscapes. As these are hard to characterize with discrete classes, mapping fractional cover as a continuous variable is highly appropriate for the assessment of savanna ecosystems. In the final $30 \mathrm{~m}$ mapping result, areas of increased woody cover can be identified for example in the area of the livestock development centre Mile 46 (Figure 2 a, highlighted in blue). These elevated shrub densities can be related to a combination of long-term high grazing pressure and reduced fire frequencies inside the fire-proof fencing of the centre. Effects of shrub clearing for agricultural land use can be likewise clearly depicted in the $30 \mathrm{~m}$ resolution map (Figure $2 \mathrm{a}$, highlighted in yellow). Both mentioned landscape characteristics are still visible in the data after aggregation to $250 \mathrm{~m}$, even though single cleared fields can not be identified reliably anymore (Figure $2 \mathrm{~b}$ ). When further aggregating the data to a cell size of $500 \mathrm{~m}$, the features become more diffuse (Figure $2 \mathrm{c}$ ). While agricultural fields can not be depicted anymore, there is still good potential to identify the areas of higher woody densities in the south of the subset.

Trees and shrubs were not discriminated in our study, due to their similar spectral properties in the study area. Not even features of shape or topology in the QuickBird data, could help to reliably distinguish between trees and big shrubs, as their crown size and shadow were very similar. The current version 3 of MODIS VCF by contrast, considers only trees equal or greater than $5 \mathrm{~m}$ in height in its layer tree cover. Shrubs are included in the layer nontree vegetation, together with grasses and croplands. Additionally, when directly comparing VCF with the results of this study, it has to be considered that during the classification of MODIS data further classification inaccuracies could have been introduced to VCF, while our results are just an aggregated version of the more accurate $30 \mathrm{~m}$ cover estimations. Despite these discrepancies, the MODIS VCF product was compared qualitatively to our results of the multi-scale approach. As an example, Figures $2 \mathrm{c}$ and $2 \mathrm{~d}$ compare subsets of the VCF layer tree cover and the corresponding woody cover values from the presented approach, scaled to $500 \mathrm{~m}$ pixel size. The region with the highest tree cover according to $\mathrm{VCF}$ is a prominent Acacia luederitzii Croton gratissimus shrub thicket (Figure $2 \mathrm{~d}$ ), highlighted in red). In fact, this area shows a remarkably lower tree, but higher woody cover than the Pterocarpus angolensis Guibourtia coleosperma association dominating the northern half of the subset [9]. When compared to own field surveys and according to the vegetation description of [9], VCF is generally characterized by an underestimation of tree cover for the North-eastern Kalahari Woodland. By mapping woody cover rather than tree cover, the characteristics of the vegetation associations of the study region could be described in a more appropriate way, even on a $500 \mathrm{~m}$-pixel scale. Moreover, it deems meaningful to derive woody cover, as this information is crucial for the analysis of many ecological key questions in savanna ecosystems, where most land surface change processes (e.g. bush encroachment, clearing for agriculture, fire impacts) become evident through changes in woody cover, rather than in tree cover only.

\section{CONCLUSIONS}

Our study showed that mapping fractional woody cover as a continuous variable is highly appropriate for the characterization of southern African savannas as these landscapes are dominated by gradual transitions between open and closed shrub- and woodlands rather than by distinct class borders. The presented approach, incorporating accurate very high resolution remote sensing 
training and validation data sets, delivered promising results. By mapping woody cover rather than tree cover, the characteristic vegetation associations of the study region could be described in an appropriate way, even on $250 \mathrm{~m}$ and 500 m-pixel scales.

The spatially explicit, quantitative information on the distribution of life forms resulting from the presented approach can be used in connection with regional models to for example identify the sensitivity of ecosystems to major drivers of land cover change and to quantify the resulting impacts on the terrestrial carbon budget. For these kinds of analyses it will be important to derive fractional herbaceous cover and bare surface proportions as well. For regional applications it will be necessary to spatially expand the mapping efforts. A viable way would be to incorporate $250 \mathrm{~m}$-MODIS time series, as it was shown that a loss of important information content occurred at a resolution of $500 \mathrm{~m}$. For multi-annual analyses it will be a challenging task to derive consistent maps for several years, especially for savanna regions of high spatio-temporal variability. The comparison of global MODIS VCF with a regional adjusted product highlights the importance of further validation initiatives based on in-situ measures and high resolution satellite imagery.

\section{ACKNOWLEDGEMENTS}

Funding from the German Federal Ministry of Education and Research (BMBF) supported this research in the framework of the Project BIOTA Southern Africa. We would also like to thank Miriam Machwitz for her very helpful contributions.

\section{REFERENCES}

[1] S. Archer, D.S. Schimel, and E.A. Holland, "Mechanisms of shrubland expansion: land use, climate or $\mathrm{CO}_{2}$ ?", Climate Change 29, pp. 91-99, 1995.

[2] H. Wagenseil, and C. Samimi, "Assessing spatio-temporal variations in plant phenology using Fourier analysis on NDVI time series: results from a dry savannah environment in Namibia", International Journal of Remote Sensing 27, pp. 3455-3471, 2006.

[3] M. Hansen, R. DeFries, J. Townshend, M. Carroll, C. Dimiceli, and R. Sohlberg, "Global Percent Tree Cover at a Spatial Resolution of 500 Meters: First Results of the MODIS Vegetation Continuous Fields Algorithm", Earth Interactions 7, pp. 1-15, 2003.

[4] M. Hansen, R. DeFries, J. Townshend, L. Marufu, and R. Sohlberg, "Development of a MODIS tree cover validation data set for Western Province, Zambia", Remote Sensing of Environment 83, pp. 320-335, 2002.
[5] T. Esch, M. Thiel, M. Bock, A. Roth and S. Dech, "Improvement of Image Segmentation Accuracy based on MultiScale Optimization Procedure", IEEE Geoscience and Remote Sensing Letters 5(3), 2008.

[6] L. Breiman, J.H. Friedman, R.A. Olshen, and C.J. Stone, Classification and Regression Trees, Chapman \& Hall, Boca Raton, 1984.

[7] M.C. Hansen, R.S. DeFries, J.R.G. Townshend, R. Sohlberg, C. Dimiceli and M. Carroll, "Towards an operational MODIS continuous field of percent tree cover algorithm: examples using AVHRR and MODIS data", Remote Sensing of Environment 83, pp. 303-319, 2002.

[8] R. DeFries, M. Hansen, and J. Townshend, "Global Discrimination of Land Cover Types from Metrics Derived from AVHRR Pathfinder Data", Remote Sensing of Environment, 54, pp. 209-222, 1995.

[9] B.J. Strohbach and A. Petersen, "Vegetation of the central Kavango woodlands in Namibia: An example from the Mile 46 Livestock Development Centre", South African Journal of Botany 73, pp. 391-401, 2007. 